\title{
Hot Tensile Deformation Behavior of Mg-4Li-1Al-0.5Y Alloy
}

\section{Ting Yang, Zhuohua Li, Jinhui Wang* and Peipeng Jin \\ Qinghai Provincial Key Laboratory of New Light Alloys, Qinghai University, Xining, China}

The microstructure evolution and deformation mechanism of the as-extruded-annealed Mg$4 \mathrm{Li}-1 \mathrm{Al}-0.5 \mathrm{Y}$ alloy (denoted as LAY410) were investigated during the hot tensile deformation at the temperatures between $150^{\circ} \mathrm{C}$ and $300^{\circ} \mathrm{C}$ with strains from $8 \times 10^{-5} \mathrm{~s}^{-1}$ to $1.6 \times 10^{-3} \mathrm{~s}^{-1}$. The results show that when the strain rate decreases and/or the deformation temperature increases, the peak stress of the alloy gradually decreases, and the elongations to fracture gradually increases. The true stress-strain curves show typical dynamic recrystallization (DRX) softening characteristics. It is observed that the microstructure in the magnesium (Mg) alloy deformed at $150^{\circ} \mathrm{C}$ is mainly composed of the deformed grains and a few recrystallized grains. The microstructures in the $\mathrm{Mg}$ alloy deformed at $200^{\circ} \mathrm{C}$ consisted of substructures and a slightly increasing number of dynamic recrystallized grains. When the deformation temperature reaches $250^{\circ} \mathrm{C}$, the number of recrystallized grains increases significantly, and the microstructures are dominated by recrystallized grains. Moreover, through theoretical calculation and result analysis, the activation energy was about $99.3 \mathrm{~kJ} / \mathrm{mol}$, and the hot tensile deformation mechanism was the alternate coordinated deformation mechanism among grain boundary slip (GBS), intragranular slip, and DRX.

Keywords: Mg-Li alloy, dynamic recrystallization (DRX), grain boundary slip, work hardening, hot tensile, deformation mechanism

\section{INTRODUCTION}

Compared with steel and aluminum (Al) alloy, $\mathrm{Mg}$ alloy not only has lower density but also good thermal conductivity and machinability. It has great application potential in aerospace, automobile manufacturing, and electronics industry (Luo et al., 1995; Wang, 2007; Hadadzadeh and Wells, 2013). However, Mg alloy is an HCP structure, and its slipping systems are less than five independent slip systems at lower temperatures (lower than $225^{\circ} \mathrm{C}$ ). Therefore, it does not meet the requirements of the five slip systems required for continuous coordinated deformation of materials (He et al., 2019), which severely limits the wider application of $\mathrm{Mg}$ alloys. When the plastic forming temperatures are higher than $225^{\circ} \mathrm{C}$, the $<\mathrm{a}>$ slipping system of the prismatic plan and $<\mathrm{c}+\mathrm{a}>$ slipping system of the pyramidal plan II can be activated, although the plastic formability of the $\mathrm{Mg}$ alloys are improved at this situation, the costs have risen.

To improve the plastic formability of $\mathrm{Mg}$ alloys at room temperature, the alloying elements such as lithium $(\mathrm{Li}), \mathrm{Al}$, zinc $(\mathrm{Zn})$, and rare earth element $(\mathrm{RE})$ are usually added to $\mathrm{Mg}$ alloys to improve its plastic formability. The literatures (Al-Samman, 2009; Tang et al., 2017; Tu et al., 2020; Wang et al., 2020) found that adding $\mathrm{Li}$ to $\mathrm{Mg}$ alloys can effectively reduce the density and lattice spacing (c/a axis ratio) of $\mathrm{Mg}$ alloys. This makes the non-basal slip system of the alloy easier to be activated during deformation, thereby effectively improving the plastic formability of the alloy. In addition, Kumar et al. (2012) found that adding $\mathrm{Li}$ to $\mathrm{Mg}-\mathrm{Al}$ alloy can promote the precipitation process of the $\mathrm{MgAlLi}_{2}$ phase, which strengthens the alloy by the precipitation phase and thus improves the mechanical properties of the alloy. However, $\mathrm{MgAlLi}_{2}$ is not thermally stable and tends to be decomposed at $50-70^{\circ} \mathrm{C}$, and is further 
TABLE 1 | Chemical composition of the LAY410 alloy (wt\%).
Material

LAY410

Mg

Composition (wt\%)

$\begin{array}{ccc}\mathrm{Li} & \mathrm{Al} & \mathrm{Y} \\ 4.26 & 1.05 & 0.52\end{array}$

decomposed to form the AlLi phase, which leads to a significant decrease in the mechanical properties of the $\mathrm{Mg}-\mathrm{Li}-\mathrm{Al}$ alloy at elevated temperatures. This phenomenon prevents $\mathrm{Mg}-\mathrm{Li}-\mathrm{Al}$ alloys from having ultra-low density and high strength simultaneously (Cui et al., 2011; Hagihara et al., 2019; Li et al., 2019). Therefore, it is important to improve the comprehensive mechanical properties of $\mathrm{Mg}-\mathrm{Li}-\mathrm{Al}$ alloy. The previous studies (Hantzsche et al., 2010; Bao et al., 2013; Zhu et al., 2014; Fei et al., 2015) have shown that the addition of rare earth element yttrium (Y) can effectively improve the comprehensive mechanical properties of $\mathrm{Mg}-\mathrm{Li}-\mathrm{Al}$ alloys. Guo et al. (2014) studied Mg-9Li-6Al- $x \mathrm{Y}(x=0,2)$ and found that adding rare earth element $\mathrm{Y}$ could not only precipitate $\mathrm{Al}_{2} \mathrm{Y}$ phase in the alloy to suppress the precipitation of AlLi phase, but effectively refine the grains as well, thus improving the comprehensive mechanical properties of the alloy. In addition, Sun et al. (2018) found that the addition of rare earth element $\mathrm{Y}$ can increase the bonding force between atoms, thus effectively inhibiting dislocation slip during deformation. Therefore, the work hardening rate in the hot deformation is increased, and the mechanical properties of the alloy at elevated temperatures are significantly improved.

Recently, many researchers have studied the hot deformation behavior and microstructure evolution of $\mathrm{Mg}-\mathrm{Li}-\mathrm{Al}$ alloy in order to improve the mechanical properties and plastic formability of the alloy (Yang et al., 2016; Chen D et al., 2020; Guo et al., 2020). Xu et al. (2015) studied the hot deformation behavior of Mg-Li-Al-Nd alloy at varied temperatures and strain rates. It is found that unlike the LAY410 alloy, in this alloy, Li exists in the form of $\beta$-Li phase. The DRX easily occurs in the $\beta$-Li phase, whereas in the $\alpha-\mathrm{Mg}$ phase, it is retarded. Moreover, the deformation temperatures and strain rates have great influence on the occurrence of DRX, and DRX can easily occur at higher temperatures and lower strain rates. Therefore, for the $\mathrm{Mg}-\mathrm{Li}-\mathrm{Al}-\mathrm{Nd}$ alloy, the improvement of plastic formability of the alloy can be attributed to DRX softening and non-basal slip system activation during the hot deformation. Li et al. (2021) studied the hot tensile deformation behavior of LAZ532 alloy. It is found that the hot tensile deformation mechanism of the alloy is more complicated, which is an alternate coordinated deformation mechanism between GBS, intragranular slip, and DRX. However, there are few reports on the hot deformation behavior of $\mathrm{Mg}-\mathrm{Li}-\mathrm{Al}-\mathrm{Y}$ alloy and the microstructure evolution during hot tensile deformation.

In this article, the microstructure evolution and deformation mechanism of LAY410 alloy during hot tensile deformation were studied in detail. Furthermore, the fracture mechanisms of LAY410 alloy during hot tensile are discussed.

\section{EXPERIMENT METHOD}

Industrial pure $\mathrm{Mg}$ (99.95 wt\%), Mg-30wt.\%Y master alloy, pure $\mathrm{Li}(99.99 \mathrm{wt} \%)$, and pure $\mathrm{Al}(99.99 \mathrm{wt} \%)$ were used as experimental
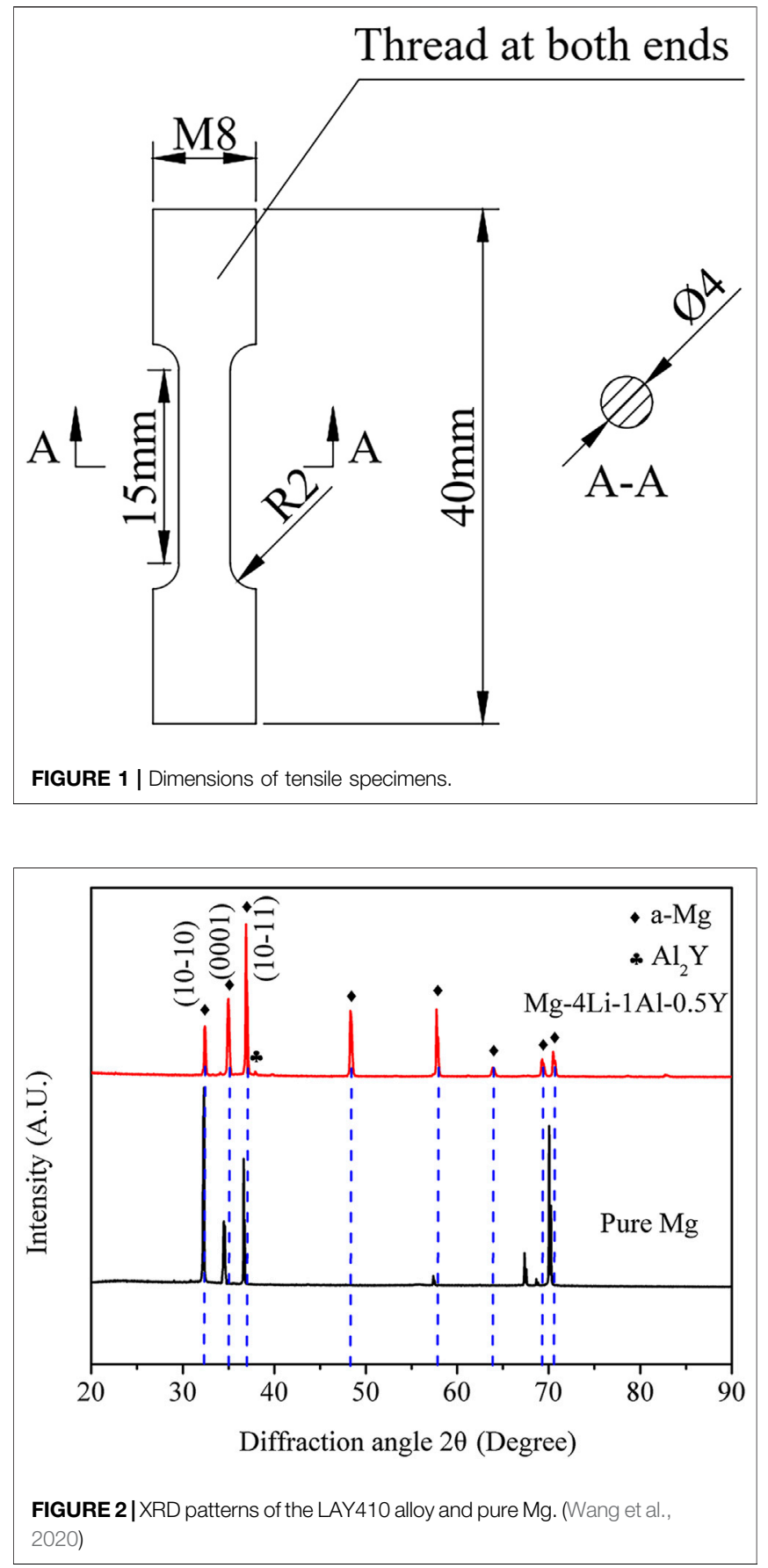

\begin{tabular}{lccc}
\hline \multicolumn{2}{l}{ TABLE 2 | Lattice parameters of $\alpha-M g}$. \\
\hline Lattice parameters & $\mathbf{A} / \mathbf{n m}$ & $\mathbf{C} / \mathbf{n m}$ & $\mathbf{c} / \mathbf{a}$ \\
\hline Pure Mg & 0.320936 & 0.521120 & 1.62375 \\
LAY410 & 0.319993 & 0.513743 & 1.60548
\end{tabular}

raw materials. The LAY410 (wt\%) alloy was fabricated by melt casting. The concrete melt-casting method is as follows. First, the clean crucible was preheated to $300^{\circ} \mathrm{C}$, and then the $\mathrm{Mg}$ ingot was placed in the crucible and the temperature was raised to $720^{\circ} \mathrm{C}$. After 
A



C

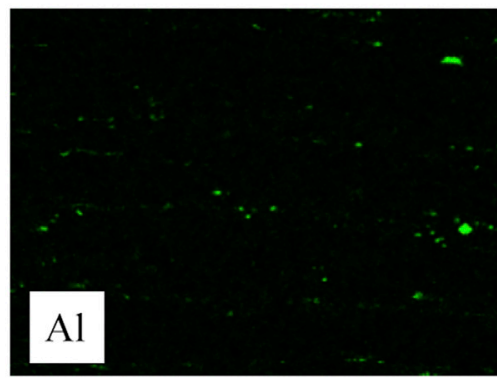

B

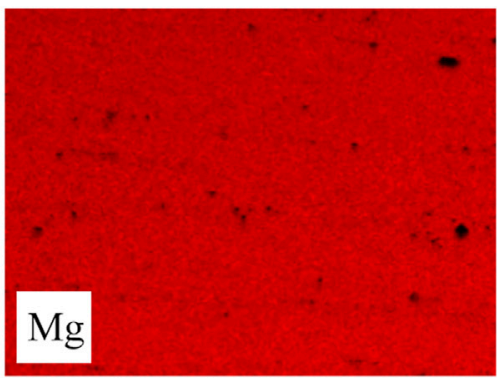

D

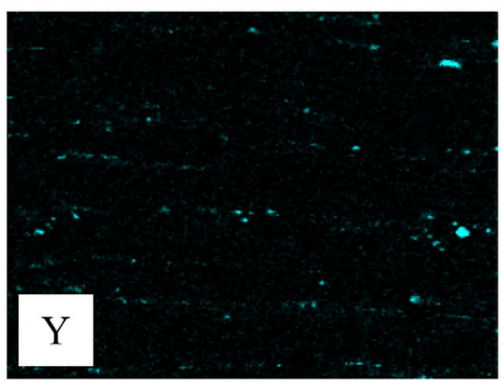

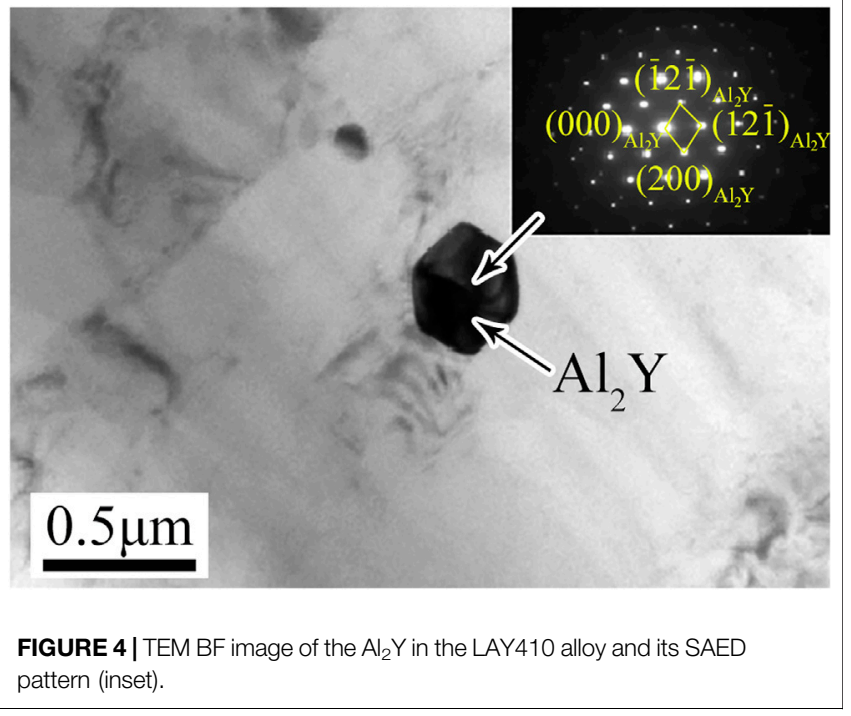

the $\mathrm{Mg}$ ingot was completely melted, the $\mathrm{Mg}-30 \mathrm{wt} \% \mathrm{Y}$ master alloy and pure $\mathrm{Al}$ were successively added into $\mathrm{Mg}$ melt, and stirred for $10 \mathrm{~min}$. Subsequently, the temperature was lowered to $680^{\circ} \mathrm{C}$ and pure $\mathrm{Li}$ was added, and stirred for $10 \mathrm{~min}$. After the temperature rose to $740^{\circ} \mathrm{C}$, the alloy melt was left standing for $20 \mathrm{~min}$, and the alloy melt was fully stirred and the slag was removed to make the melt clear and clean. Finally, after the melt temperature was further reduced to $710^{\circ} \mathrm{C}$, the alloy melt was cast into a mold to obtain a LAY410 alloy ingot. During the whole melting process, sulfur hexafluoride $\left(\mathrm{SF}_{6}\right)$ and argon (Ar) were used as a mixed shielding gas. Next, the ingot was processed into an extruded billet of $\varnothing 44 \mathrm{~mm} \times 40 \mathrm{~mm}$ and held at $350^{\circ} \mathrm{C}$ for $2 \mathrm{~h}$. Then, the four-column hydraulic press (equipment model: IM-Y300) was used to extrude at an extrusion ratio of 13:1 and then air cooling was performed to obtain an extruded bar with a diameter of $12 \mathrm{~mm}$. Finally, the extruded sample was put into a heat treatment furnace at $350^{\circ} \mathrm{C}$ and then taken out and water cooled immediately after holding for $1 \mathrm{~h}$ to prevent the grain growth and retain the grain structure. The alloy was called the LAY410 alloy.

The actual chemical composition of the prepared LAY410 alloy tested by inductively coupled plasma optical emission spectrometer (ICP-OES) is shown in Table 1. As can be seen from Table 1, the actual content of each element in the alloy has a small gap with the design composition, indicating that there was almost no element burning loss in the smelting process. After heat preservation for $10 \mathrm{~min}$, the hot tensile test of the LAY410 alloy was carried out at temperatures between $150^{\circ} \mathrm{C}$ and $300^{\circ} \mathrm{C}$ with the strain rates from $8 \times$ $10^{-5} \mathrm{~s}^{-1}$ to $1.6 \times 10^{-3} \mathrm{~s}^{-1}$ via an Instron-5982 equipped with a heating device. The tensile specimens were prepared along the extrusion direction (ED), and their dimensions are shown in Figure 1. Furthermore, through scanning electron microscopy (SEM, ZEISS-6035 field-emission) and electron back-scattering diffraction (EBSD) technology, the microstructure of the specimens after hot tensile deformation was analyzed to explore the microstructure evolution during hot tensile deformation.

\section{RESULTS AND DISCUSSIONS}

\section{Analysis of Phases and Microstructures in the Alloy}

The X-ray diffraction (XRD) patterns of LAY410 alloy as shown in our previous study (Wang et al., 2020) (Figure 2 in this article). There are not only diffraction peaks of the $\alpha-M g$ phase, but the 

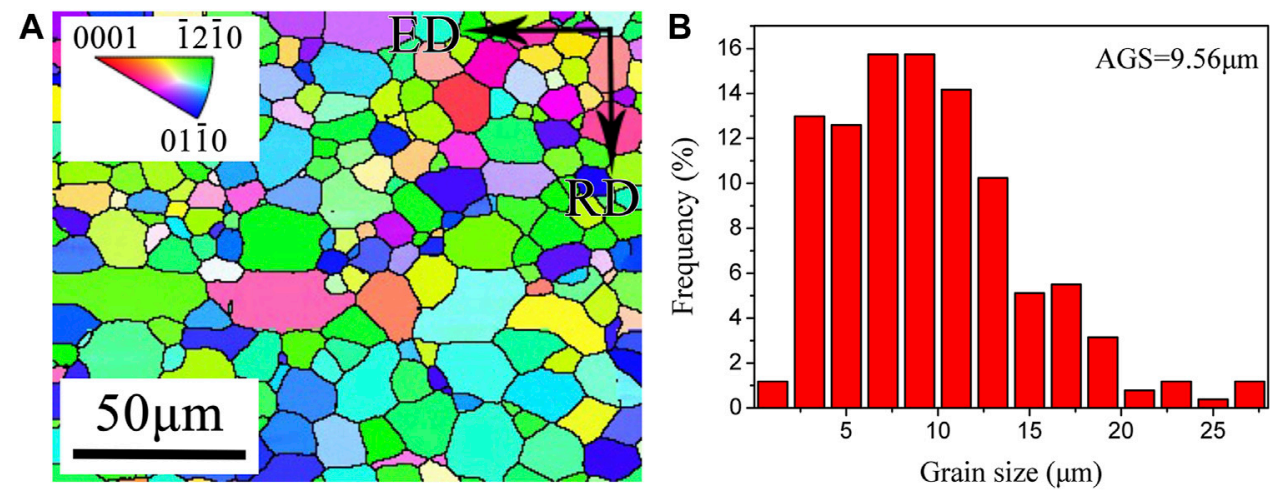

C

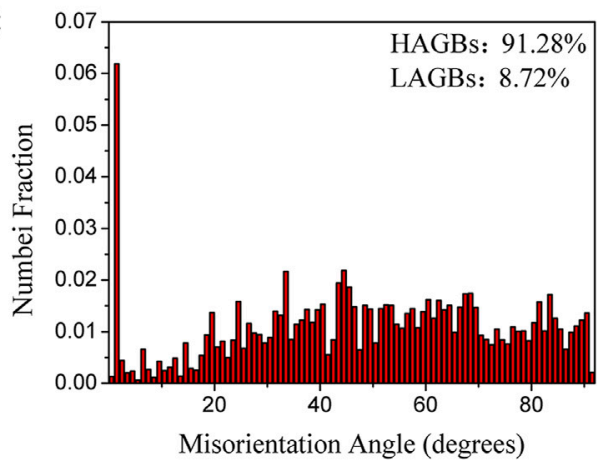

D

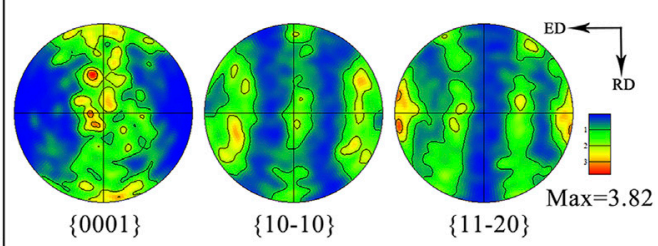

FIGURE 5 | Microstructure and texture of the LAY410 alloy: (A) inverse pole figure, (B) grain size map, (C) misorientation angle distribution histogram, (D) pole figures.

diffraction peaks of the $\mathrm{Al}_{2} \mathrm{Y}$ phase as well. There is only one diffraction peak of the $\mathrm{Al}_{2} \mathrm{Y}$ phase with a low intensity in the XRD patterns due to the high solid solubility of Y in Mg (Stanford et al., 2015). Most of the $\mathrm{Y}$ atoms are dissolved in the $\mathrm{Mg}$ matrix. As a result, the content of $\mathrm{Al}_{2} \mathrm{Y}$ phase formed in LAY410 alloy is very low. In addition, compared with pure $\mathrm{Mg}$, the diffraction peak of the $a-M g$ phase in LAY410 alloy is shifted to the right, which indicates that the axial ratio value (c/a) of the $\alpha-M g$ phase decreases as described in our previous study (Wang et al., 2020) and the results are reanalyzed in this article. In order to confirm the above conclusions, Jade 6.0 software is used to calculate the lattice constants of the $\alpha-\mathrm{Mg}$ phase in pure $\mathrm{Mg}$ and LAY410 alloy. The calculated results are shown in Table 2. Compared with pure $\mathrm{Mg}$, the lattice constants a and c of the $\alpha-\mathrm{Mg}$ phase in $\mathrm{Mg}-\mathrm{Li}$ alloy are reduced by 0.29 and $1.41 \%$, respectively. The axial ratio value (c/a) value dropped from 1.624 to 1.605 . This is mainly because when the added amount of $\mathrm{Li}$ is less than $5.7 \%$, it can be completely dissolved in $\mathrm{Mg}$, thereby reducing the axial ratio value (c/a) of $\mathrm{Mg}$ (Koike et al., 2005; Zhou et al., 2017).

To prove the existence of $\mathrm{Al}_{2} \mathrm{Y}$ phase in LAY410 alloy, further, EDS-Mapping of the alloy is carried out as shown in Figure 3. It can be clearly observed from Figure 3 that a small amount of submicron white precipitates are distributed in the grain boundary and grain interior, and the main elements are $\mathrm{Al}$ and $\mathrm{Y}$. Combined with the binary phase diagram of Al-Y alloy (Liu et al., 2004), it is concluded that the white precipitated phase in Figure $\mathbf{3 A}$ is the $\mathrm{Al}_{2} \mathrm{Y}$ phase. In addition, by observing the transmission electron microscope (TEM) bright-field image of the precipitated phase as shown in Figure $\mathbf{4}$ and the corresponding selected area electron diffraction pattern (inset), it is further proved that the white particles in the alloy are of the $\mathrm{Al}_{2} \mathrm{Y}$ phase. Because the $\mathrm{Al}_{2} \mathrm{Y}$ phase is a hard phase, it can hinder the dislocation movement. Therefore, the formation of $\mathrm{Al}_{2} \mathrm{Y}$ phase can improve the strength of LAY410 alloy effectively due to dispersion strengthening (Zhao et al., 2016).

In order to determine the grain size and texture type of LAY410 alloy, EBSD technology is used to characterize the alloy. The results are shown in Figure 5. From Figures 5A,B, it can be seen that there are a large number of equiaxed grains in the alloy. And there are many fine recrystallized grains around the equiaxed grains. The average grain size (AGS) is $9.56 \mu \mathrm{m}$. As shown in Figure 5C, the misorientation angle of the alloy is mainly high-angle grain boundaries (HAGBs $>10^{\circ}$ ) with a number fraction of 91.28 . This also proves that there is a large amount of DRX in the alloy, which weakens the $\{0001\}$ basal fiber texture due to forming fresh DRXed grains without a preferred orientation selection. Figure 5D shows the polar figure of the LAY410 alloy, where ED and RD represent the extrusion direction and radial direction, respectively. The pole density points in the $\{0001\}$ pole figure are distributed along the $\mathrm{RD}$, while the pole density points in the $\{10-10\}$ and $\{11-20\}$ pole figures are distributed along the edges. This indicates that there is a weak $\{0001\}$ basal fiber texture in the alloy, and its texture strength value is 3.82 . 

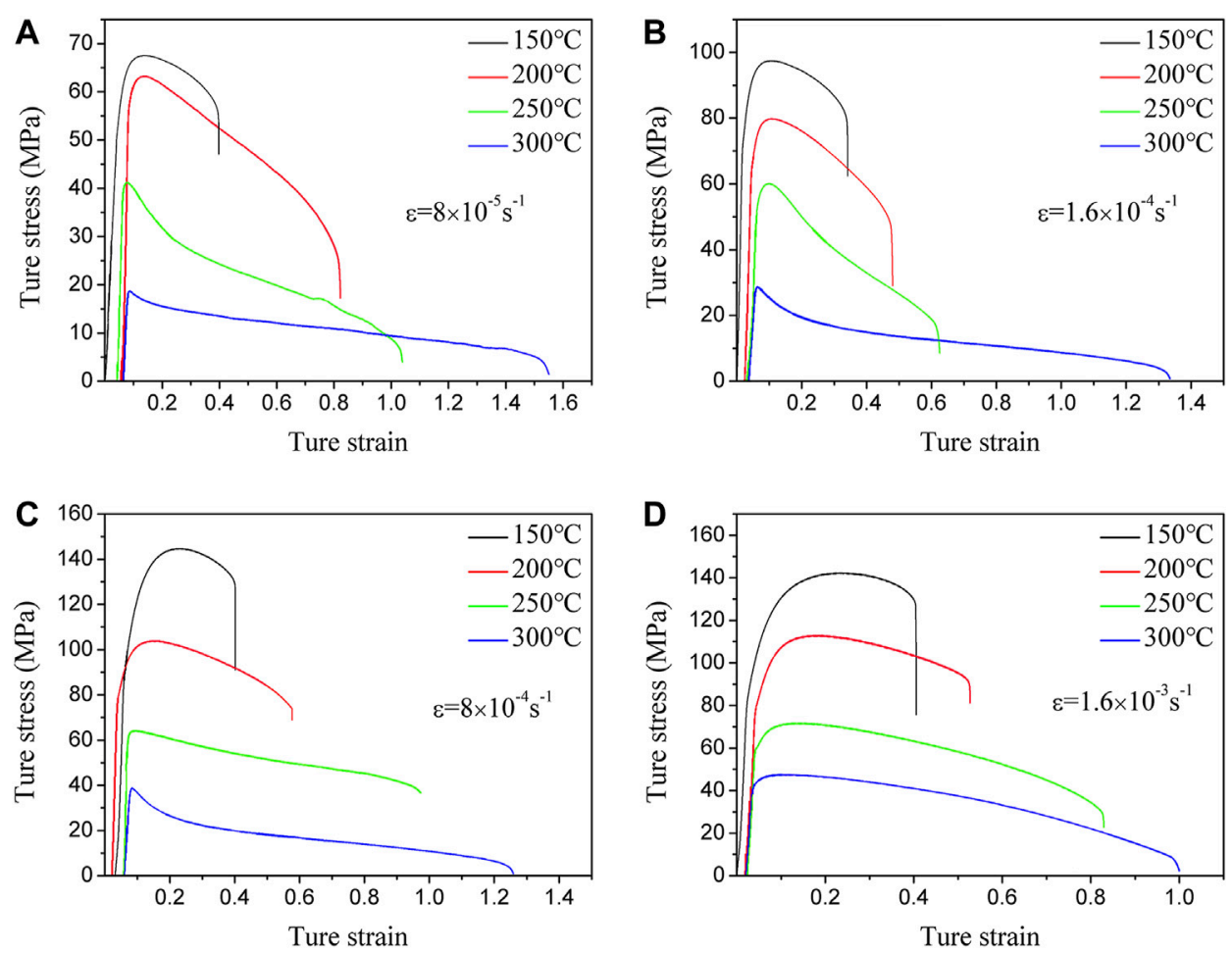

FIGURE 6 | True stress-strain curves of the LAY410 alloy: (A) $\varepsilon=8 \times 10^{-5} \mathrm{~s}^{-1}$, (B) $\varepsilon=1.6 \times 10^{-4} \mathrm{~s}^{-1}$, (C) $\varepsilon=8 \times 10^{-4} \mathrm{~s}^{-1}$, and (D) $\varepsilon=1.6 \times 10^{-3} \mathrm{~s}^{-1}$.

\section{High-Temperature Mechanical Properties of Alloy}

The hot tensile true stress-strain curves of LAY410 alloy at the temperatures between $150^{\circ} \mathrm{C}$ and $300^{\circ} \mathrm{C}$ with strain rates from $8 \times$ $10^{-5} \mathrm{~s}^{-1}$ to $1.6 \times 10^{-3} \mathrm{~s}^{-1}$ are shown in Figure 6. According to the observation of the curves, the alloy exhibits a typical DRX softening curve. This is mainly due to the decrease in the axial ratio value (c/a) of the alloy, which leads to the increase in dislocation density and the occurrence of cross-slip. It is conducive to nucleation of DRX, causing a certain degree of dynamic softening (Yang et al., 2009; Li et al., 2011). In addition, the strain rate and deformation temperature have a significant effect on the flow stress of the alloy. The flow stress gradually decreases with the strain rate decrease and/or deformation temperature increase. That is, the curves show a positive strain rate effect and negative temperature effect. The change of flow stress curve is mainly manifested in three stages. In the elastic deformation stage, the true-stress increases sharply due to the volumetric expansion, but the shape remaining unchanged of the crystal induced an increase in the distance of atoms in the $\alpha-\mathrm{Mg}$ HCP crystal structure (Huang and Huang, 2013). The flow stress rapidly increases to the critical stress. The second stage of tensile deformation is the deformation process in which the flow stress reaches the peak stress from the critical stress after yielding. The strain hardening effect caused by dislocation proliferation is gradually offset by the strain softening effect caused by partial dislocation annihilation. This causes the dislocation propagation rate to decrease gradually until it reaches equilibrium with the dislocation annihilation rate. At this time, the flow stress reaches the peak stress, and the strain hardening rate gradually decreases to zero. The third stage of tensile deformation is the process in which the flow stress gradually decreases until the specimen fracture. As the strain increases, the dislocation annihilation rate is gradually greater than the dislocation propagation rate. It makes the strain softening effect stronger than the strain hardening effect, leading to the strain softening phenomenon in the rheological curve (Xu et al., 2009).

\section{Effect of Deformation Temperature on Microstructure of Alloy}

To further investigate the influence of deformation temperatures on the hot tensile deformation behavior of the alloy, the microstructures at the same strain position of the hot tensile specimen are selected for analysis at the same strain rate $(\varepsilon=1.6 \times$ $\left.10^{-4} \mathrm{~s}^{-1}\right)$ with different deformation temperatures $(\mathrm{T}=$ $150^{\circ} \mathrm{C}-250^{\circ} \mathrm{C}$ ).

The IPF maps, grain boundary maps, and misorientation angle distribution histograms near the fracture of the hot tensile specimen of LAY410 alloy at the same rate $(\varepsilon=1.6 \times$ $\left.10^{-4} \mathrm{~s}^{-1}\right)$ with different deformation temperatures $\left(\mathrm{T}=150^{\circ} \mathrm{C}\right.$, $200^{\circ} \mathrm{C}, 250^{\circ} \mathrm{C}$ ) are shown in Figure 7. As shown in Figure 7A, when the deformation temperature is $150^{\circ} \mathrm{C}$, the microstructures near the fracture of tensile specimen are mainly composed of fine recrystallized grains and coarse deformed grains. The 

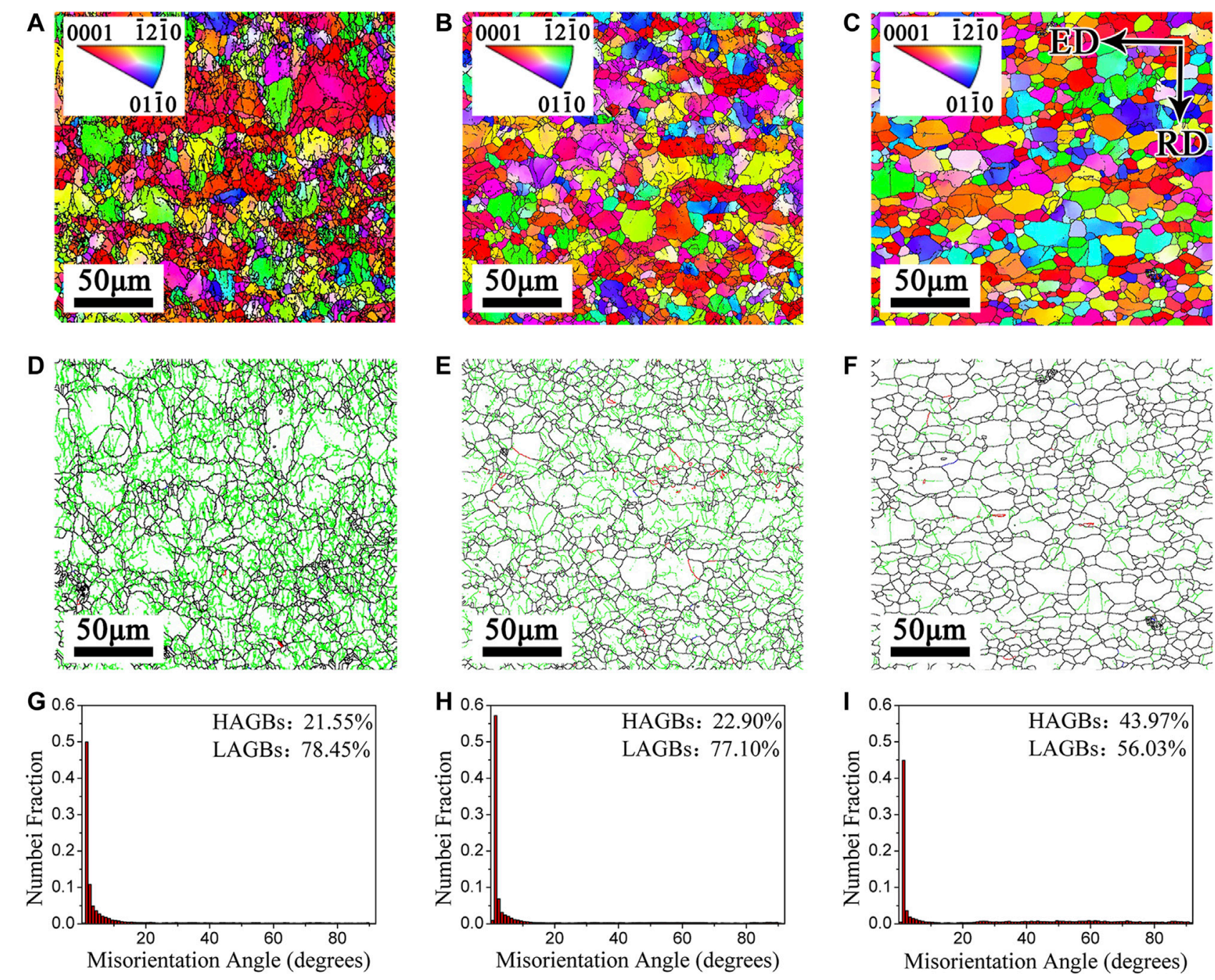

FIGURE 7 | IPF maps, grain boundary maps, and misorientation angle distribution histograms of the LAY410 alloy at the same rate with different temperatures: (A,D,G) $\mathrm{T}=150^{\circ} \mathrm{C},(\mathbf{B}, \mathbf{E}, \mathbf{H}) \mathrm{T}=200^{\circ} \mathrm{C},(\mathbf{C}, \mathbf{F}$, and $\mathbf{I}) \mathrm{T}=250^{\circ} \mathrm{C}$.

recrystallized grains are mainly distributed at the trigeminal grain boundaries composed of coarse deformed grains, which show obvious discontinuous dynamic recrystallization (DDRX) characteristics. And the traces of the band-like structure can still be seen in the Figure 7A, indicating that some of the crystal grains are not fully rotated and are still connected in series to show a band-like shape. In addition, there is a clear color orientation gradient inside the coarse crystals, which indicates that there are abundant slip activities inside. The corresponding grain boundary distribution of size angle is shown in Figure 7D, where the green line represents LAGBs and the black line represents HAGBs. It can be seen that a large number of LAGBs are mainly distributed in the coarse grains and at the grain boundaries, which indicates that there are a large number of dislocations inside the coarse deformed grains. As shown in Figure 7G, the corresponding misorientation angle is mainly concentrated in LAGBs with a number fraction of $78.45 \%$. It shows that the microstructures in the $\mathrm{Mg}$ alloy are mainly composed of the deformed grains and a few of the recrystallized grains. As the deformation temperature increases to $200^{\circ} \mathrm{C}$, the fine recrystallized structure inside the alloy increases slightly, and the grain size is mostly kept between 10 and $20 \mu \mathrm{m}$, as shown in Figures $\mathbf{7 B}, \mathbf{E}, \mathbf{H}$. In addition, the LAGBs inside the coarse deformed grains also decreased slightly, and the corresponding misorientation angle shifted slightly to the HAGBs. When the deformation temperature reaches $250{ }^{\circ} \mathrm{C}$, the recrystallized grain structure inside the alloy increases significantly, at this time, HAGBs with a number fraction of $22.90 \%$, as shown in Figures 7C,F,I. The crystal grains rotate and connect to a network and begin to grow up. It is clearly observed that the content of the LAGBs inside the coarse grains is lowered, the number fraction of which is reduced to $56.03 \%$, and the corresponding misorientation angle is obviously shifted to the HAGBs. This is mainly due to the increase in temperature that accelerates the grain boundaries migration and further promotes the occurrence of complete DRX (Chen T et al., 2020). This leads 

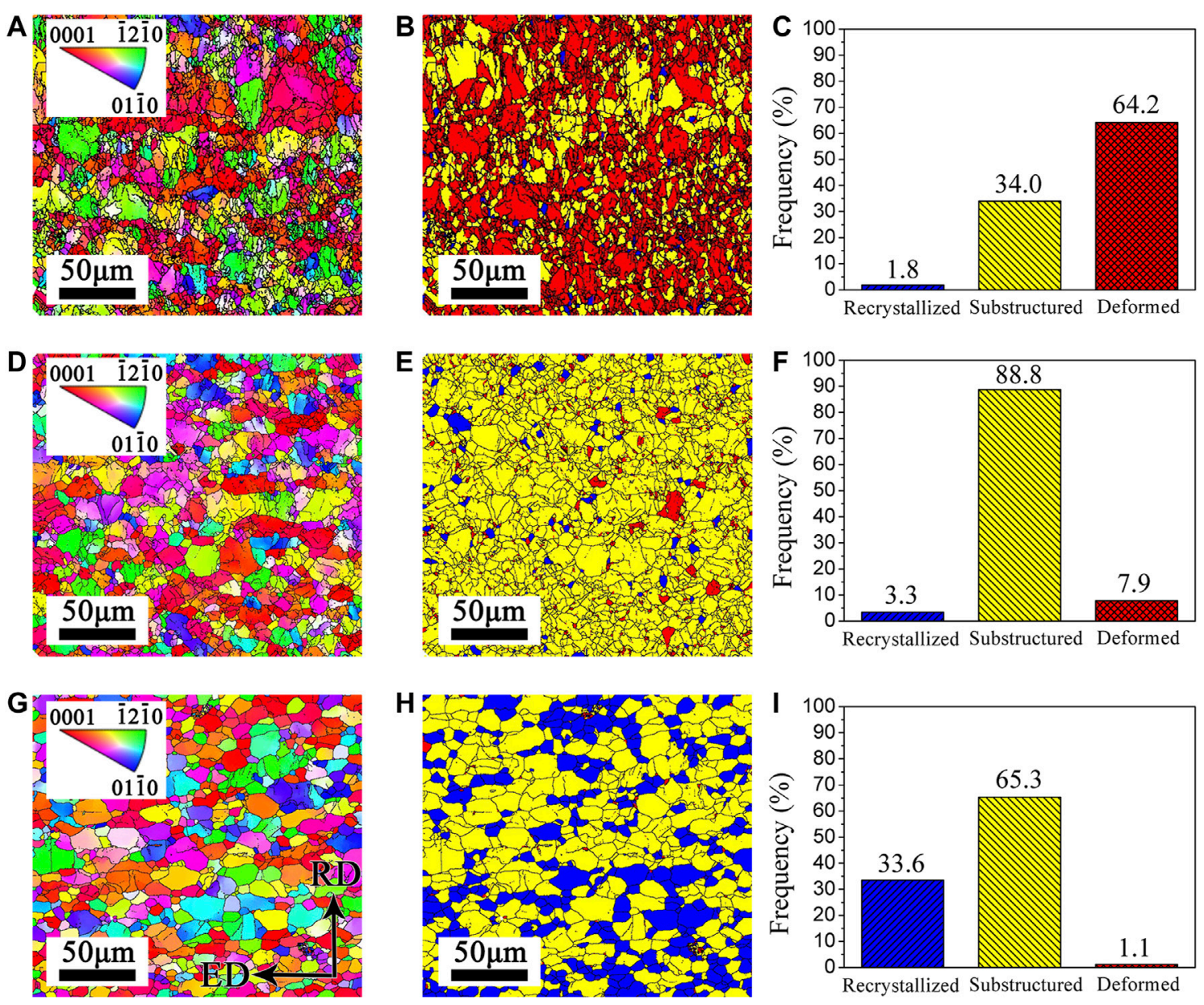

FIGURE 8 | Microstructures of the LAY410 alloy at the same rate with different temperatures: $(\mathbf{A}, \mathbf{B}, \mathbf{C}) \mathrm{T}=150^{\circ} \mathrm{C}, \mathbf{( D , E , F ) ~} \mathrm{T}=200^{\circ} \mathrm{C}, \mathbf{( G , H , I ) ~} \mathrm{T}=250^{\circ} \mathrm{C}$.

to an increase in the HAGBs and a decrease in the LAGBs. Small new grains without distortion are produced in the original deformed structure, which makes the overall grain size significantly reduced (Sun et al., 2019).

The distribution of microstructures and the proportion of each microstructure near the fracture of the hot tensile specimens of LAY410 alloy at the same rate $\left(\varepsilon=1.6 \times 10^{-4} \mathrm{~s}^{-1}\right)$ with different deformation temperatures $\left(\mathrm{T}=150^{\circ} \mathrm{C}, 200^{\circ} \mathrm{C}, 250^{\circ} \mathrm{C}\right)$ are shown in Figure 8. The red, yellow, and blue grains in the Figure 8 represent deformed grains, substructure and recrystallized grains, respectively. As shown in Figures $\mathbf{8 A - C}$, when the deformation temperature is $150^{\circ} \mathrm{C}$, the microstructures of the alloy are mainly composed of deformed grains and substructures, with a number fraction of 64.2 and $34.0 \%$, respectively. The recrystallized grains accounted for only a small part, with a number fraction of $1.8 \%$. It indicates that $\mathrm{DRX}$ is incomplete at $150^{\circ} \mathrm{C}$, which is consistent with the results in Figure 7 . At $150^{\circ} \mathrm{C}$, recrystallization is mainly distributed at the intersection of deformed grains and substructures. This is mainly because not only the grain boundary energy is high at the intersection, but dislocation plugging is prone to occur, resulting in a high dislocation density. Therefore, it is conducive to DRX. Related studies
(Malik et al., 2020) have shown that the nucleation temperature of DRX in $\mathrm{Mg}$ alloys is about $200^{\circ} \mathrm{C}$. In this experiment, the nucleation of DRX can be observed clearly at $150^{\circ} \mathrm{C}$, indicating that the decrease in axial ratio value $(\mathrm{c} / \mathrm{a})$ is conducive to the nucleation of DRX. As shown in Figures 8D-F, when the deformation temperature reaches $200^{\circ} \mathrm{C}$, the deformed grains decrease significantly, and the alloy structure is mainly composed of substructures. The number of dynamic recrystallized grains increased slightly, indicating that the DRX is nucleating and growing. As the diffusion speed between atoms and the migration speed of grain boundaries are accelerated, dislocations are more likely to slip and may be accompanied by cross-slip. Therefore, it is conducive to substructures formation and DRX. When the temperature reaches $250^{\circ} \mathrm{C}$, the phenomenon of DRX becomes more obvious and the number increases significantly (see Figures 8G-I). It indicates that when the temperature is higher, the rate of DRX and growth is faster. With the recrystallized grains increase, the softening degree caused by recrystallized grains also increases. Therefore, DRX also contributes to the increase in alloy elongation (Hadadzadeh et al., 2018). In summary, with the deformation temperature increases, the atomic diffusion rate increases. The nucleation and 

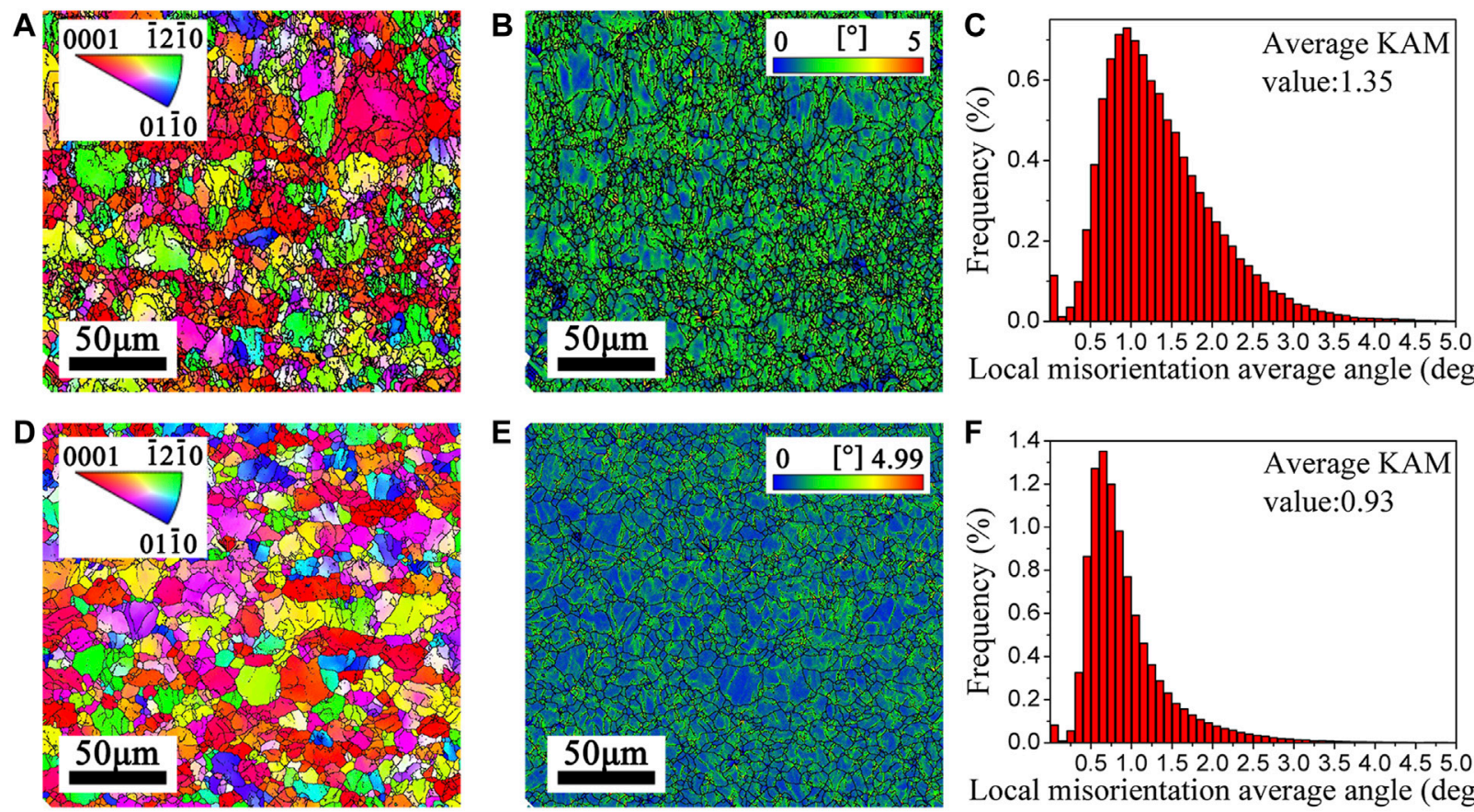

Local misorientation average angle (degrees)
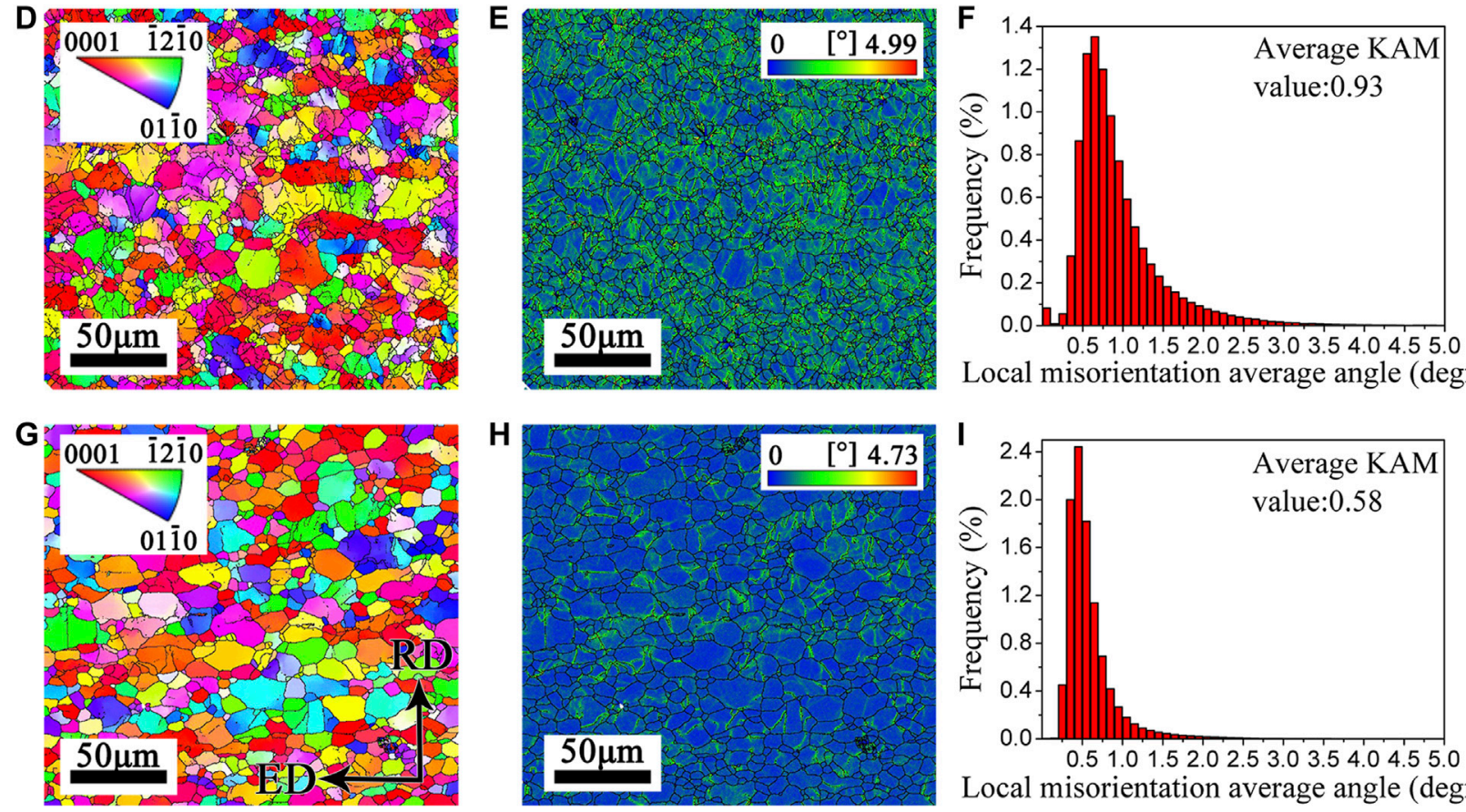

Local misorientation average angle (degrees)

FIGURE 9 | KAM maps of the LAY410 alloy at the same rate with different temperatures: (A,B, and C) $\mathrm{T}=150^{\circ} \mathrm{C},(\mathbf{D}, \mathbf{E}, \mathbf{F}) \mathrm{T}=200^{\circ} \mathrm{C},(\mathbf{G}, \mathbf{H}, \mathbf{I}) \mathrm{T}=250^{\circ} \mathrm{C}$.

growth of dynamic recrystallized grains are promoted, which leads to flow stress decrease and elongation increase.

The kernel average misorientation (KAM) maps near the fracture of the hot tensile specimen of LAY410 alloy at the same rate $\left(\varepsilon=1.6 \times 10^{-4} \mathrm{~s}^{-1}\right)$ with different deformation temperatures $\left(\mathrm{T}=150^{\circ} \mathrm{C}, 200^{\circ} \mathrm{C}\right.$, and $\left.250^{\circ} \mathrm{C}\right)$ are shown in Figure 9. KAM value is an indicator of defect density, especially dislocation density, and can indirectly reflect deformation mechanism. It means that the evolution of dislocation density at different temperatures can be reflected in the KAM diagrams during tensile. When the deformation temperature is $150^{\circ} \mathrm{C}$, the average KAM value is 1.35, as shown in Figures 9A-C. Meanwhile, the internal stress in the alloy is relatively concentrated, the dislocation density is relatively high, and the internal defects are relatively high. The number of dynamic recrystallized grains is small, and no obvious twins are observed. Therefore, the deformation mechanism is dominated by slippage, and the nucleation of a small number of recrystallized grains plays an auxiliary role in coordinating deformation. As the deformation temperature increases, the average KAM value decreases to 0.58 , as shown in Figures 9D-I. Due to the occurrence of DRX, the stress in the alloy is released, and the stress concentration phenomenon is alleviated, resulting in a significant reduction in internal defects of the alloy. There is no obvious stress concentration phenomenon, only a small amount of stress is concentrated at the LAGBs.

The polar figures near the fracture of the hot tensile specimen of LAY410 alloy at the same rate $\left(\varepsilon=1.6 \times 10^{-4} \mathrm{~s}^{-1}\right)$ with different deformation temperatures $\left(\mathrm{T}=150^{\circ} \mathrm{C}, 200^{\circ} \mathrm{C}, 250^{\circ} \mathrm{C}\right)$ are shown in Figure 10. As can be seen from Figure 10A, when the deformation temperature is $150^{\circ} \mathrm{C}$, the polar density points of $\{0001\}$ basal plane are distributed along RD. The polar density points of $\{11-20\}$ plane and $\{10-10\}$ plane are distributed along the edge, showing a typical $\{0001\}$ basal plane fiber texture, that is, the $\{0001\}$ basal plane of the grains is approximately parallel to the $\mathrm{ED}$, and the texture strength is 9.66 . When the deformation temperature reaches $200^{\circ} \mathrm{C}$, as shown in Figure 10B, the texture distribution becomes random. The texture strength is reduced, and its value is 8.31 , but there is no significant change in the 
A

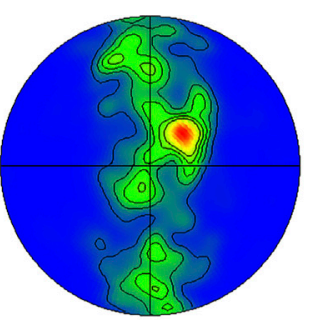

$\{0001\}$



$\{0001\}$

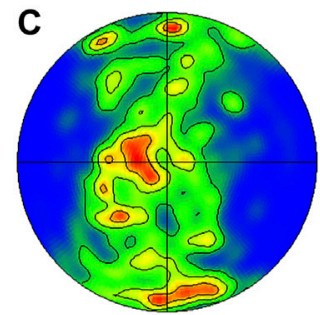

$\{0001\}$

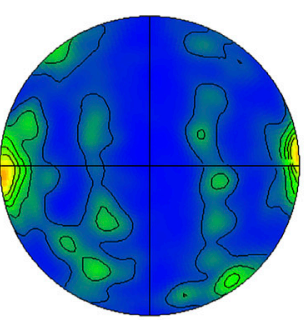

$\{10-10\}$

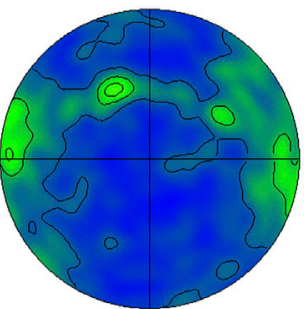

$\{10-10\}$

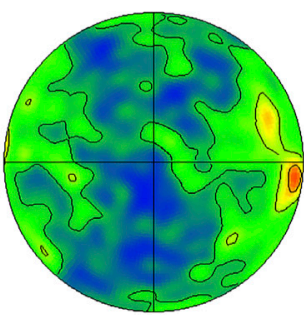

$\{10-10\}$
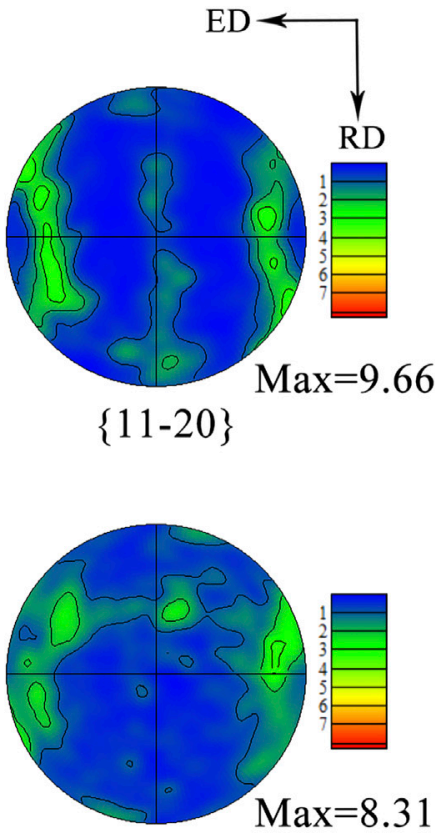

$\{11-20\}$

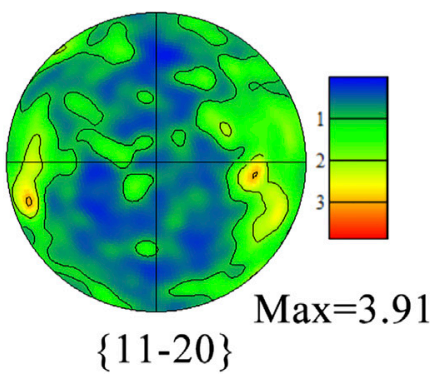

FIGURE 10 | Pole figures of the LAY410 alloy at the same rate with different temperatures: (A) $\mathrm{T}=150^{\circ} \mathrm{C}$, (B) $\mathrm{T}=200^{\circ} \mathrm{C}$, (C) $\mathrm{T}=250^{\circ} \mathrm{C}$.

texture type. The increase in temperature is conducive to nonbasal slip system activation, which leads to the randomization of alloy texture and the decrease in texture strength (Barrett et al., 2018). When the temperature reaches $250^{\circ} \mathrm{C}$, the texture strength decreases to 3.91 , as shown in Figure 10C. The recrystallized grain structure inside the alloy increases significantly, which leads to a significant decrease in the texture strength. In general, the above results indicate that the deformation temperature has a certain influence on the texture strength of the alloy but does not change the texture type. Therefore, the $\{0001\}$ basal fiber texture of LAY410 alloy still exists after hot tensile deformation.

\section{Hot Tensile Fracture Morphology of Alloy}

The fracture morphologies of LAY410 alloy after tensile at the same rate $\left(\varepsilon=1.6 \times 10^{-4} \mathrm{~s}^{-1}\right)$ with different deformation temperatures $\left(\mathrm{T}=150^{\circ} \mathrm{C}, 200^{\circ} \mathrm{C}\right.$, and $\left.250^{\circ} \mathrm{C}\right)$ is shown in Figure 11. It can be seen from Figure 11 that the presence of cleavage steps, dimples, and quasi-cleavage tearing ridges leads to uneven fracture after hot tensile, showing the characteristics of ductile-brittle mixed fracture. When the temperature is $150^{\circ} \mathrm{C}$, the existence of grain boundary indicates that the fracture mechanism is intergranular fracture. As the temperature reaches $250^{\circ} \mathrm{C}$, the number of dimples gradually increases and the color of dimples becomes darker. It shows that the dominated fractures mechanisms of the alloys are gradually transferred from the fragile fracture mechanism to the ductile dimple mechanism due to the stress relaxation and the microstructure homogenization induced by DRX increase as deformation temperatures elevated (Bao et al., 2021).

\section{Hot Tensile Plastic Deformation Mechanism of Alloy}

To investigate the plastic deformation mechanism of LAY410 alloy during hot tensile, the Arrhenius model is used to calculate the relationship between various factors and flow stress during deformation. Its specific expression is shown in Eq. 1 (Ji et al., 2011):

$$
\dot{\varepsilon}=A \sigma^{n} \exp \left(-\frac{Q}{R T}\right)
$$



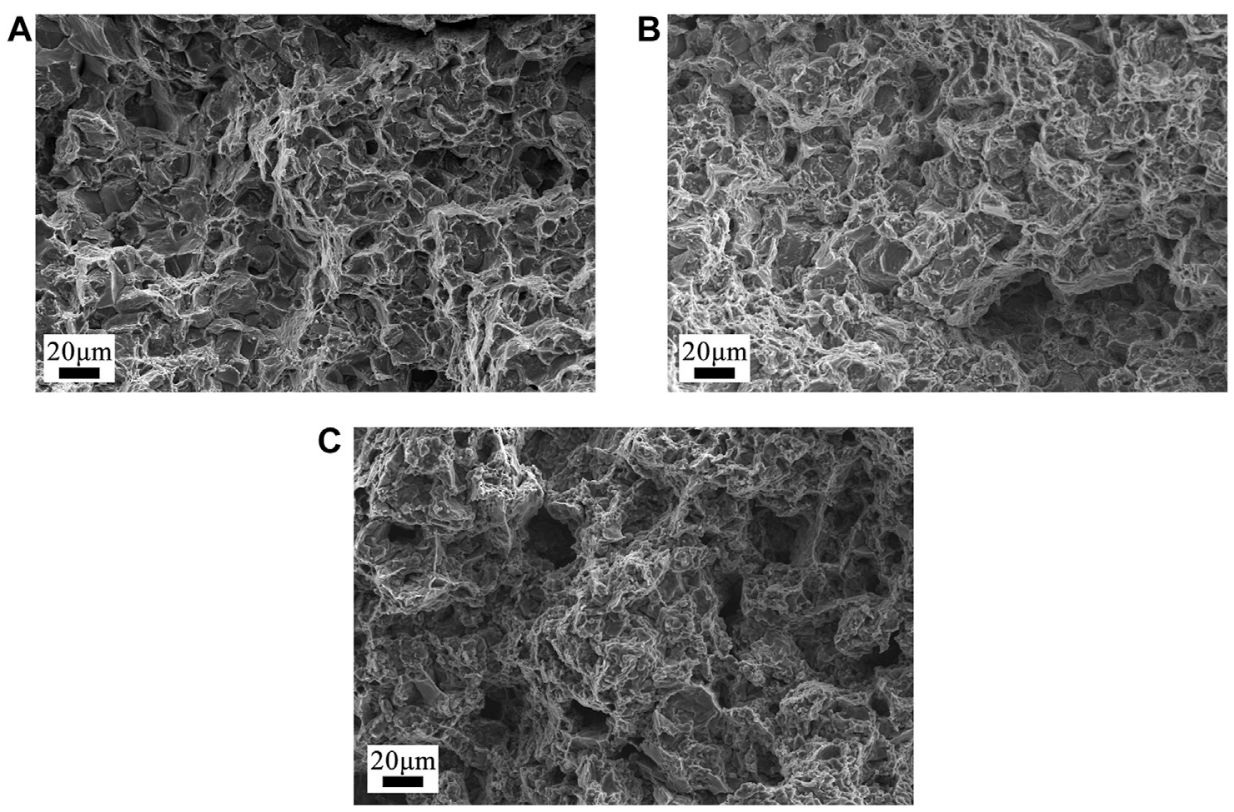

FIGURE 11 | Fracture morphologies of the LAY410 alloy at the same rate with different temperatures: (A) $\mathrm{T}=150^{\circ} \mathrm{C}$, (B) $\mathrm{T}=200^{\circ} \mathrm{C}$, (C) $\mathrm{T}=250^{\circ} \mathrm{C}$.

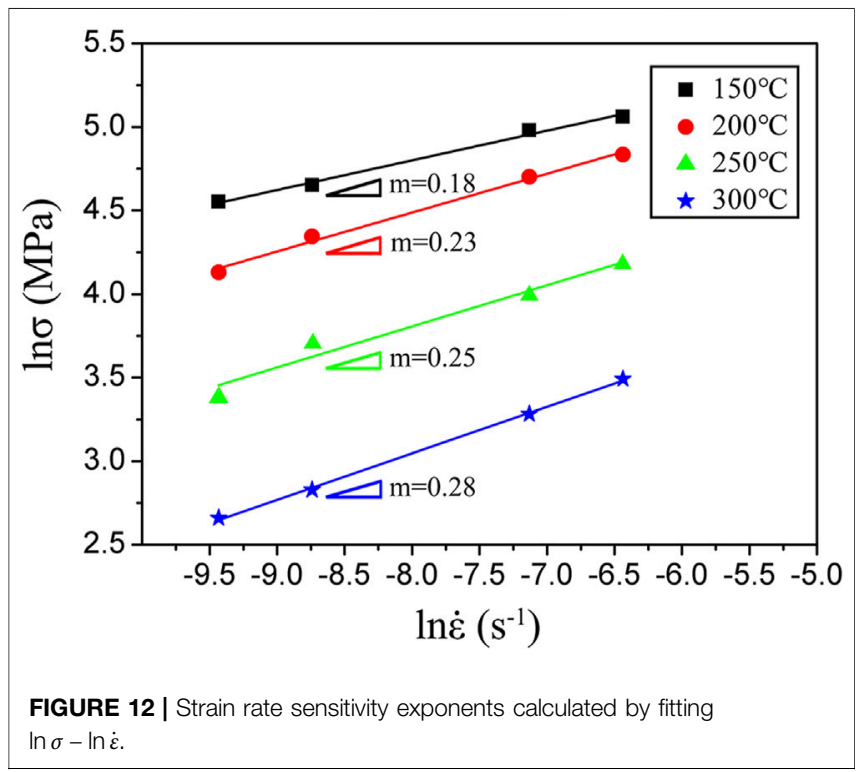

where $\dot{\varepsilon}$ is the strain rate, $\sigma$ is the flow stress, Q is the activation energy, $\mathrm{T}$ is the deformation temperature, $\mathrm{R}$ is the molar gas constant, and its value is $8.314 \mathrm{Jmol}^{-1} \mathrm{k}^{-1}$. A and $\mathrm{n}$ are the material constants, $n=1 / \mathrm{m}$. $\mathrm{m}$ is the strain rate sensitivity exponent, usually used to reflect the upper limit of the plastic deformation of metal materials.

When the deformation temperature and strain rate are both constants, the strain rate sensitivity exponent can be calculated by Eq. 2 (Huang et al., 2014) as follows:

$$
m=\frac{\partial \ln \sigma}{\partial \ln \varepsilon} \mid \varepsilon, T,
$$

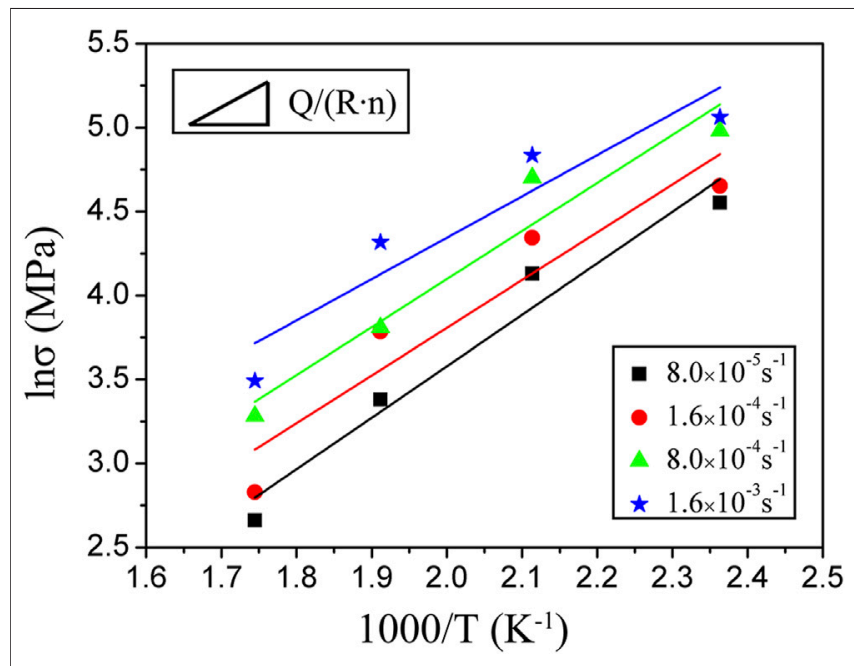

FIGURE 13 | Activation energies calculated by linear fitting.

where $\sigma$ represents the flow stress and $\dot{\varepsilon}$ represents the strain rate.

When the deformation temperatures are $150^{\circ} \mathrm{C}, 200^{\circ} \mathrm{C}, 250^{\circ} \mathrm{C}$, and $300^{\circ} \mathrm{C}$, and the strain rates are $8 \times 10^{-5} \mathrm{~s}^{-1}, 1.6 \times 10^{-4} \mathrm{~s}^{-1}$, $8 \times 10^{-4} \mathrm{~s}^{-1}$, and $1.6 \times 10^{-3} \mathrm{~s}^{-1}$, the calculated results are shown in Figure 12. According to the analysis, it is obvious that as the deformation temperature increases from $150^{\circ} \mathrm{C}$ to $300^{\circ} \mathrm{C}$, the $\mathrm{m}$ value gradually increases from 0.18 to 0.28 . In general, the value of $\mathrm{m}$ is used to reflect the ability to inhibit local necking. When the value of $\mathrm{m}$ is larger, the ability to inhibit tensile necking is stronger, indicating that the alloy exhibits higher elongation. When $\mathrm{m}=1$, the alloy reaches the ideal infinitely extendable state. Therefore, it can be concluded that LAY410 alloy shows 
good plastic formability when the deformation temperature is $300^{\circ} \mathrm{C}$.

To calculate activation energies in Eq. 1, Equation 1 is converted into Eq. 3:

$$
\dot{\varepsilon} \cdot \exp \left(\frac{Q}{R T}\right)=A \sigma^{n} .
$$

Take the natural logarithm on both sides of Eq. 3 to obtain Eq. 4 which is as follows:

$$
\ln \sigma=\frac{\ln \dot{\varepsilon}-\ln A}{n}+\frac{1}{T} \cdot \frac{Q}{R \cdot n} .
$$

Eq. 4 can be further expressed as follows:

$$
Q=R \cdot n \cdot\left|\frac{\partial \ln \sigma}{\partial(1 / T)}\right|_{\dot{\varepsilon}}=R \cdot \frac{1}{m} \cdot\left|\frac{\partial \ln \sigma}{\partial(1 / T)}\right|_{\dot{\varepsilon}}
$$

By linear fitting $\ln \sigma-\ln 1 / T$, the relevant slope can be obtained, and the calculation results are shown in Figure 13. Finally, by substituting the values of $Q /(R \cdot n)$ into Eq. 4 , it can be obtained that the activation energy of the alloy is about $99.3 \mathrm{~kJ} /$ mol, which is smaller than the lattice diffusion activation energy of pure $\mathrm{Mg}(135 \mathrm{~kJ} / \mathrm{mol})$ and slightly higher than the grain boundary diffusion activation energy of pure $\mathrm{Mg}(92 \mathrm{~kJ} / \mathrm{mol})$ (Atkins, 1984). Therefore, based on the above analysis, it is further proved that the dominant hot tensile deformation mechanism of LAY410 alloy is the alternate coordinated deformation mechanism among GBS, intragranular slip, and DRX.

\section{CONCLUSION}

1) In the LAY410 alloy, with the strain rate decreases and/or deformation temperature increases, the peak stress gradually decreases and the elongations to fracture gradually increases. In addition, with temperature increases, an obvious steadystate rheological characteristic appears at the later stage of deformation, and the fracture morphology of the alloy gradually transfers from the ductile-brittle mixed fracture mode to the ductile fracture mode.

2) The microstructures of LAY410 alloy are obviously different at varied temperatures. When the deformation temperature is low $\left(\mathrm{T}=150^{\circ} \mathrm{C}\right)$, the alloy microstructures are mainly

\section{REFERENCES}

Al-Samman, T. (2009). Comparative Study of the Deformation Behavior of Hexagonal Magnesium-Lithium Alloys and a Conventional Magnesium AZ31 alloy. Acta Materialia 57, 2229-2242. doi:10.1016/j.actamat.2009.01.031 Atkins, A. G. (1984). Deformation-mechanism Maps (The Plasticity and Creep of Metals and Ceramics). J. Mech. Working Tech. 9, 224-225. doi:10.1016/03783804(84)90015-9

Bao, J., Wu, Z., Wu, S., Withers, P. J., Li, F., Ahmed, S., et al. (2021). Hot DwellFatigue Behaviour of Additively Manufactured AlSi10Mg alloy: Relaxation, Cyclic Softening and Fracture Mechanisms. Int. J. Fatigue 151, 106408. doi:10.1016/j.ijfatigue.2021.106408 composed of deformed grains with LAGBs. There are many internal defects in the alloy, and the recrystallized grains nucleate but the number is small. When the temperature rises to $250^{\circ} \mathrm{C}$, the number of recrystallized grains increases significantly, and the DRX is completed more fully.

3) The deformation mechanism of LAY410 alloy is affected by temperature. When the deformation temperature is low, the deformation of the alloy is dominated by slippage, and the twinning plays a supplementary coordinating role. When the deformation temperature is high, DRX plays a dominant role.

4) In the LAY410 alloy, the activation energy of hot tensile deformation is about $99.3 \mathrm{~kJ} / \mathrm{mol}$, and the hot tensile deformation mechanism is the alternate coordinated deformation mechanism among GBS, intragranular slip, and DRX.

\section{DATA AVAILABILITY STATEMENT}

The raw data supporting the conclusions of this article will be made available by the authors, without undue reservation.

\section{AUTHOR CONTRIBUTIONS}

TY wrote and organized the manuscript. JW conducted the final review and revision of the manuscript. ZL and PJ made important contribution in the revision. All authors approved it for publication.

\section{FUNDING}

The authors would like to express thanks to the financial support from the Science and Technology Department of Qinghai Province (No. 2018-ZJ-783).

\section{ACKNOWLEDGMENTS}

We acknowledge Mengna Zhang for assistance in SEM, TEM, and EBSD experiments.

Bao, L., Le, Q., Zhang, Z., Cui, J., and Li, Q. (2013). Effect of Homogenization Treatment on Microstructure Evolution and the Distributions of RE and $\mathrm{Zr}$ Elements in Various Mg-Li-RE-Zr Alloys. J. Magnesium Alloys 1, 139-144. doi:10.1016/j.jma.2013.07.003

Barrett, C. D., Imandoust, A., and El Kadiri, H. (2018). The Effect of Rare Earth Element Segregation on Grain Boundary Energy and Mobility in Magnesium and Ensuing Texture Weakening. Scripta Materialia 146, 46-50. doi:10.1016/ j.scriptamat.2017.11.004

Chen, D., Xu, S., and Kulkarni, Y. (2020). Atomistic Mechanism for VacancyEnhanced Grain Boundary Migration. Phys. Rev. Mater. 4, 33602. doi:10.1103/ PhysRevMaterials.4.033602

Chen, T., Chen, Z., Shao, J., Wang, R., Mao, L., and Liu, C. (2020). The Role of Long Period Stacking Ordered Phase in Dynamic Recrystallization of a Mg-Zn-Y 
alloy during Hot Compression. J. Alloys Comp. 818, 152814. doi:10.1016/ j.jallcom.2019.152814

Cui, C., Wu, L., Wu, R., Zhang, J., and Zhang, M. (2011). Influence of Yttrium on Microstructure and Mechanical Properties of As-Cast Mg-5Li-3Al-2Zn alloy. J. Alloys Comp. 509, 9045-9049. doi:10.1016/j.jallcom.2011.04.030

Fei, P., Qu, Z., and Wu, R. (2015). Microstructure and Hardness of Mg-9Li-6Al- X $\mathrm{La}(\mathrm{X}=0,2,5)$ Alloys during Solid Solution Treatment. Mater. Sci. Eng. A 625, 169-176. doi:10.1016/j.msea.2014.12.014

Guo, F., Liu, L., Ma, Y., Jiang, L., Zhang, D., and Pan, F. (2020). Mechanism of Phase Refinement and its Effect on Mechanical Properties of a Severely Deformed Dual-phase Mg-Li alloy during Annealing. Mater. Sci. Eng. A 772, 138792. doi:10.1016/j.msea.2019.138792

Guo, X., Wu, R., Zhang, J., Liu, B., and Zhang, M. (2014). Influences of Solid Solution Parameters on the Microstrucuture and Hardness of Mg-9Li-6Al and Mg-9Li-6Al-2Y. Mater. Des. 53, 528-533. doi:10.1016/j.matdes.2013.07.011

Hadadzadeh, A., Mokdad, F., Amirkhiz, B. S., Wells, M. A., Williams, B. W., and Chen, D. L. (2018). Bimodal Grain Microstructure Development during Hot Compression of a Cast-Homogenized Mg-Zn-Zr alloy. Mater. Sci. Eng. A 724, 421-430. doi:10.1016/j.msea.2018.03.112

Hadadzadeh, A., and Wells, M. A. (2013). Mathematical Modeling of ThermoMechanical Behavior of Strip during Twin Roll Casting of an AZ31 Magnesium alloy. J. Magnesium Alloys 1, 101-114. doi:10.1016/j.jma.2013.04.001

Hagihara, K., Mori, K., and Nakano, T. (2019). Enhancement of Plastic Anisotropy and Drastic Increase in Yield Stress of Mg-Li Single Crystals by Al-Addition Followed by Quenching. Scripta Materialia 172, 93-97. doi:10.1016/ j.scriptamat.2019.07.012

Hantzsche, K., Bohlen, J., Wendt, J., Kainer, K. U., Yi, S. B., and Letzig, D. (2010). Effect of Rare Earth Additions on Microstructure and Texture Development of Magnesium alloy Sheets. Scripta Materialia 63, 725-730. doi:10.1016/ j.scriptamat.2009.12.033

He, J., Mao, Y., Lu, S., Xiong, K., Zhang, S., Jiang, B., et al. (2019). Texture Optimization on $\mathrm{Mg}$ Sheets by Preparing Soft Orientations of Extension Twinning for Rolling. Mater. Sci. Eng. A 760, 174-185. doi:10.1016/j.msea.2019.06.007

Huang, K. Z., and Huang, Y. G. (2013). Advanced Solid Mechanics. Beijing: Tsinghua University Press. in Chinese.

Huang, Y.-C., Lin, Y. C., Deng, J., Liu, G., and Chen, M.-S. (2014). Hot Tensile Deformation Behaviors and Constitutive Model of 42CrMo Steel. Mater. Des. 53, 349-356. doi:10.1016/j.matdes.2013.06.070

Ji, G., Li, F., Li, Q., Li, H., and Li, Z. (2011). A Comparative Study on Arrheniustype Constitutive Model and Artificial Neural Network Model to Predict HighTemperature Deformation Behaviour in Aermet100 Steel. Mater. Sci. Eng. A 528, 4774-4782. doi:10.1016/j.msea.2011.03.017

Koike, J., Kobayashi, T., Mukai, T., Watanabe, H., Suzuki, M., Maruyama, K., et al. (2005). The Activity of Non-basal Slip Systems and Dynamic Recovery at Room Temperature in fine-grained AZ31B Magnesium Alloys. Acta Mater. 51, 2055-2065. doi:10.1016/S1359-6454(03)00005-3

Kumar, V., Govind, R., Balasubramaniam, R., and Balani, K. (2012). Microstructure Evolution and Texture Development in Thermomechanically Processed Mg-Li-Al Based Alloys. Mater. Sci. Eng. A 547, 38-50. doi:10.1016/j.msea.2012.03.074

Li, J., Qu, Z., Wu, R., Zhang, M., and Zhang, J. (2011). Microstructure, Mechanical Properties and Aging Behaviors of As-Extruded Mg-5Li-3Al-2Zn-1.5Cu alloy. Mater. Sci. Eng. A 528, 3915-3920. doi:10.1016/j.msea.2011.01.025

Li, X., Cheng, C., Le, Q., Zhou, X., Liao, Q., Chen, X., et al. (2019). Ex-situ EBSD Analysis of Yield Asymmetry, Texture and Twinning Development in Mg-5Li3Al-2Zn alloy during Tensile and Compressive Deformation. J. Alloys Comp. 805, 947-956. doi:10.1016/j.jallcom.2019.07.099

Li, X., Le, Q., Li, D., Wang, P., Jin, P., Cheng, C., et al. (2021). Hot Tensile Deformation Behavior of Extruded Laz532 alloy with Heterostructure. Mater. Sci. Eng. A 801, 140412. doi:10.1016/J.MSEA.2020.140412

Liu, T., Wang, Y. D., Wu, S. D., Peng, R. L., Huang, C. X., Jiang, C. B., et al. (2004). Textures and Mechanical Behavior of Mg-3.3\%Li alloy after ECAP. Scr. Mater. 51, 1057-1061. doi:10.1016/j.scriptamat.2004.08.007

Luo, A., Renaud, J., Nakatsugawa, I., and Plourde, J. (1995). Magnesium Castings for Automotive Applications. JOM 47, 28-31. doi:10.1007/BF03221226

Malik, A., Wang, Y., Huanwu, C., Nazeer, F., Ahmed, B., Khan, M. A., et al. (2020). Constitutive Analysis, Twinning, Recrystallization, and Crack in fine-grained
ZK61 Mg alloy during High Strain Rate Compression over a Wide Range of Temperatures. Mater. Sci. Eng. A 771, 138649. doi:10.1016/j.msea.2019.138649 Stanford, N., Marceau, R. K. W., and Barnett, M. R. (2015). The Effect of High Yttrium Solute Concentration on the Twinning Behaviour of Magnesium Alloys. Acta Materialia 82, 447-456. doi:10.1016/j.actamat.2014.09.022

Sun, Y., Wang, R., Peng, C., and Feng, Y. (2018). Effects of Sn and Y on the Microstructure, Texture, and Mechanical Properties of As-Extruded Mg-5Li3Al-2Zn alloy. Mater. Sci. Eng. A 733, 429-439. doi:10.1016/j.msea.2018.05.030

Sun, Y., Wang, R., Ren, J., Peng, C., and Feng, Y. (2019). Hot Deformation Behavior of Mg-8Li-3Al-2Zn-0.2Zr alloy Based on Constitutive Analysis, Dynamic Recrystallization Kinetics, and Processing Map. Mech. Mater. 131, 158-168. doi:10.1016/j.mechmat.2019.02.005

Tang, Y., Le, Q., Jia, W., Fu, L., Liu, X., and Cui, J. (2017). Microstructure evolution and strengthening mechanism study of Mg-Li alloys during deformation and heat treatment. Materials Science and Engineering: A 704, 344-359. doi:10.1016/j.msea.2017.08.043

Tu, T., Chen, X., Zhao, C., Yuan, Y., and Pan, F. (2020). A simultaneous increase of elastic modulus and ductility by $\mathrm{Al}$ and $\mathrm{Li}$ additions in Mg-Gd-Zn-Zr-Ag alloy. Materials Science and Engineering: A 771, 138576.1-138576.5. doi:10.1016/ j.msea.2019.138576

Wang, J., Zhang, M., Shi, B., Zhang, L., and Jin, P. (2020). Ex-situ EBSD Investigation of the Reduced $\mathrm{C} / \mathrm{a}$ Values and Work Hardening Behavior in Mg-4Li-1Al-0.5Y alloy under Hot Compression. Mater. Sci. Eng. A 797, 140113. doi:10.1016/j.msea.2020.140113

Wang, X. L. (2007). Preparation of Mg-Li Mg-Li-Zr Zn-Zr Alloys by Electrolysis in Molten Salt. Harbin: Harbin Institute of Technology.

Xu, S. W., Kamado, S., Matsumoto, N., Honma, T., and Kojima, Y. (2009). Recrystallization Mechanism of As-Cast AZ91 Magnesium alloy during Hot Compressive Deformation. Mater. Sci. Eng. A 527, 52-60. doi:10.1016/ j.msea.2009.08.062

Xu, T. C., Peng, X. D., Qin, J., Chen, Y. F., Yang, Y., and Wei, G. B. (2015). Dynamic Recrystallization Behavior of Mg-Li-Al-Nd Duplex alloy during Hot Compression. J. Alloys Comp. 639, 79-88. doi:10.1016/j.jallcom.2015.03.144

Yang, X., Wang, G., Dong, G., Gong, F., Gong, F., and Zhang, M. (2009). Rare Earth Conversion Coating on Mg-8.5Li Alloys. J. Alloys Comp. 487, 64-68. doi:10.1016/j.jallcom.2009.07.113

Yang, Y., Peng, X., Ren, F., Wen, H., Su, J., and Xie, W. (2016). Constitutive Modeling and Hot Deformation Behavior of Duplex Structured Mg-Li-Al-Sr alloy. J. Mater. Sci. Tech. 32, 1289-1296. doi:10.1016/j.jmst.2016.11.015

Zhao, J., Zhang, J., Liu, W., Wu, G., and Zhang, L. (2016). Effect of Y Content on Microstructure and Mechanical Properties of As-Cast Mg-8Li-3Al-2Zn alloy with Duplex Structure. Mater. Sci. Eng. A 650, 240-247. doi:10.1016/ j.msea.2015.10.067

Zhou, Y., Chen, Z., Ji, J., and Sun, Z. (2017). Dynamic Nano Precipitation Behavior of As-Cast Mg-4Li-4Zn-Y alloy during High Temperature Deformation. Mater. Sci. Eng. A 707, 110-117. doi:10.1016/j.msea.2017.09.050

Zhu, T., Sun, J., Cui, C., Wu, R., Betsofen, S., Leng, Z., et al. (2014). Influence of Y and $\mathrm{Nd}$ on Microstructure, Texture and Anisotropy of Mg-5Li-1 Al alloy. Mater. Sci. Eng. A 600, 1-7. doi:10.1016/j.msea.2014.02.017

Conflict of Interest: The authors declare that the research was conducted in the absence of any commercial or financial relationships that could be construed as a potential conflict of interest.

Publisher's Note: All claims expressed in this article are solely those of the authors and do not necessarily represent those of their affiliated organizations, or those of the publisher, the editors and the reviewers. Any product that may be evaluated in this article, or claim that may be made by its manufacturer, is not guaranteed or endorsed by the publisher.

Copyright (๑) 2021 Yang, Li, Wang and Jin. This is an open-access article distributed under the terms of the Creative Commons Attribution License (CC BY). The use, distribution or reproduction in other forums is permitted, provided the original author(s) and the copyright owner(s) are credited and that the original publication in this journal is cited, in accordance with accepted academic practice. No use, distribution or reproduction is permitted which does not comply with these terms. 